\title{
Effect of Lead Additions on Microstructure and Casting Properties of AZ91 Magnesium Alloy
}

\author{
Erkan Koc ${ }^{1,}$, , Mehmet Unal ${ }^{2}$, Yunus Turen ${ }^{1}$, Halil Ahmet Goren ${ }^{3}$, Ercan Candan ${ }^{4}$ \\ ${ }^{1}$ Department of Metallurgy and Materials, Faculty of Engineering, Karabuk University, Karabük, Turkey \\ ${ }^{2}$ Department of Metal, Faculty of Technical Education, Karabuk University, Karabük, Turkey \\ ${ }^{3}$ Mechatronics Program, Vocational School, Sinop University, Sinop, Turkey \\ ${ }^{4}$ Department of Mechanical and Manufacturing Engineering, Bilecik University, Bilecik, Turkey
}

Email address:

ekoc@karabuk.edu.tr (E. Koc)

${ }^{*}$ Corresponding author

To cite this article:

Erkan Koc, Mehmet Unal, Yunus Turen, H. Ahmet Goren, Ercan Candan. Effect of Lead Additions on Microstructure and Casting Properties of AZ91 Magnesium Alloy. International Journal of Materials Science and Applications. Vol. 7, No. 1, 2018, pp. 13-17.

doi: 10.11648/j.ijmsa.20180701.13

Received: November 7, 2017; Accepted: November 24, 2017; Published: January 2, 2018

\begin{abstract}
In this study, the effect of Pb element addition varied between $0.2-0.4$ wt. $\%$ on the microstructure and casting properties of AZ91 magnesium alloy were investigated. The microstructural results showed that as increasing $\mathrm{Pb}$ additions into the AZ91 alloy, the grains and the $\mathrm{Mg}_{17} \mathrm{Al}_{12}$ intermetallic phase becomes thinner. When examining the effect on casting properties; It was observed that the fluidity of AZ91 alloy increased as the increasing of $\mathrm{Pb}$ additions. In the hot tear tests two different mold systems were used. Hot tearing were observed in the longest section in the tests using "the mold same diameter, different lengths" and when the "the mold different diameter, same lengths" were used, hot tears were observed in all of the molds with diameters of $6,8,10 \mathrm{~mm}$. Hot tearings were observed in $0.2 \mathrm{wt} . \%$ and $0.3 \mathrm{wt} . \% \mathrm{~Pb}$ additions, while hot tearing was not observed when this ratio increased to $0.4 \%$ for the $12 \mathrm{~mm}$ diameter test specimens. There was also not hot tearing were observed in any sample when the sample diameter was $16 \mathrm{~mm}$.
\end{abstract}

Keywords: Magnesium, AZ91, Fluidity, Hot Tearing

\section{Introduction}

Due to its low density, magnesium based alloys are the lightest structural metal in terms of many engineering applications such as portable microelectronics, telecommunications, aeraspace and automobile industry. The weight of $\mathrm{Mg}$ is $36 \%$ of $\mathrm{Al}(\mathrm{Al})$, of iron ( $\mathrm{Fe}$ ) and $78 \%$ of that of steel [1]. The main reason why the automotive industry has the biggest interest in the $\mathrm{Mg}$ alloys from the automotive sector today is the reduction in vehicle weight with the use of light $\mathrm{Mg}$ alloys fuel economy and as a consequence gas emissions can be reduced [2,3]. AZ91 Mg alloy, formed by alloying Mg-Al-Zn elements, is mainly used for casting automobile parts. Compared with other Mg alloys, AZ91 is the most widely used commercial alloy due to its mechanical and casting properties [4]. Casting products are obtained by adding alloying elements in order to improve the structural properties of magnesium. $\mathrm{Mg}$ has a hexagonal lattice structure and its particle diameter permits solid solubility with a large number of elements.

When $\mathrm{Mg}$ is used as a structural material, it generally has a high strength / weight ratio when alloyed with the elements. The most commonly used alloy element in $\mathrm{Mg}$ alloys is Aluminum. In Mg-based alloys Al improves solid precipitation hardening, melt castability and reduces microporosity of $\mathrm{Mg}$ cast alloys. Besides, $\mathrm{Al}$ improves hardness, stiffness and solidification time of $\mathrm{Mg}$ alloys while reducing ductility. Alloy strength of $\mathrm{Mg}$ - $\mathrm{Al}$ alloys is developed by formation of $\mathrm{Mg}_{17} \mathrm{Al}_{12}$ intermetallics at low temperatures $\left(\leq 120^{\circ} \mathrm{C}\right)$. However, the tendency of alloys to micropores increases with increasing $\mathrm{Al}$ content [5-7]. $\mathrm{Zn}$ is limited to $2 \%$ due to precipitation hardening, which 
increases resistance to ambient temperatures and at the same time increases castability and precipitation into grain boundaries, resulting in hot tearing. Si reduces the castability and fluidity of $\mathrm{Mg}$ alloys $[5,6,8]$. Si atoms form $\mathrm{Mg}_{2} \mathrm{Si}$ intermetallic in solid state at room temperature [9]. The addition of alloying elements such as $\mathrm{Sb}, \mathrm{Ca}, \mathrm{Bi}, \mathrm{Pb}$ and rare earth (RE) to the AZ91 alloy were investigated to improve the casting, microstructural stability or creep properties of the alloy [10-12].

In the literature there are few studies on the effect of $\mathrm{Pb}$ addition on the casting and microstructure properties of AZ91 alloy. Although $\mathrm{Pb}$ vapor is detrimental to health, the addition of a small amount may not be a serious problem as long as proper care is taken [13]. The aim of this work is to investigate the effects of $\mathrm{Pb}$ addition on casting properties such as microstructure properties and castability and hot tear on AZ91 alloy.

\section{Experimental Studies}

The $\mathrm{Mg}, \mathrm{Al}, \mathrm{Zn}$ ingots with a minimum purity of $99.9 \%$ were purchased from Karasu Metal Co., Turkey. Pure Mg and $\mathrm{Al}$ were melted at $750^{\circ} \mathrm{C}$ under a protective $\mathrm{Ar}$ gas in a graphite crucible. The analyzes of the alloys used in the tests are given in Table $1 . \mathrm{Zn}$ and $\mathrm{Pb}$ additions were alloyed $1 \mathrm{~min}$ before casting to avoid losses of $\mathrm{Zn}$ and $\mathrm{Pb}$ due to vapourisation. The molten alloy was then cast into a cast iron mould (preheated to $250^{\circ} \mathrm{C}$ ) having $30 \mathrm{~mm}$ diameter and 170 $\mathrm{mm}$ length under protective $\mathrm{SF}_{6}$ gas.

Table 1. Chemical compositions of the alloys.

\begin{tabular}{llllll}
\hline \multirow{2}{*}{ Alloy } & \multicolumn{6}{l}{ Compositions wt.\% } & & \\
\cline { 2 - 6 } & Al & Zn & Mn & Pb & Mg \\
\hline AZ91 & 9.13 & 0.78 & 0.18 & - & \\
AZ91+\%0.2Pb & 9.19 & 0.81 & 0.21 & 0.21 & Balance \\
AZ91+\%0.3Pb & 9.21 & 0.84 & 0.22 & 0.29 & \\
AZ91+\%0.4Pb & 9.18 & 0.87 & 0.22 & 0.39 & \\
\hline
\end{tabular}

Casting operations were carried out at $250^{\circ} \mathrm{C}$ which ensures optimum casting conditions by supplying $\mathrm{SF}_{6}$ shielding gas [14]. A mold heating furnace which is capable of reaching a temperature of $300^{\circ} \mathrm{C}$ was used to remove the test molds to the desired temperature. For metallographic inspection, the surfaces of the samples were ground using pure water with 400 and 600 mesh SiC paper and polished with $1 \mu \mathrm{m}$ alumina paste. $5 \mathrm{ml}$ of acidic acid, $10 \mathrm{ml}$ of picric acid, $10 \mathrm{ml}$ of distilled water and $100 \mathrm{ml}$ of ethyl alcohol were used as the etchant. Microstructure studies were carried out on a Nikon Epiphot 200 optical microscope.

Flowing spirals were used for flow tests, and die cast molds with different diameters for hot tearing tests were used. Spirality of fluency used M. Di Sabatino et al. [15] and hot tear mold Cao and Kou [16] are of the same shape and dimensions as those used in their work. In addition, molds were prepared from cast iron for microstructure studies. In Figure 1, mold images and tensile test specimens used in the experiments are given.

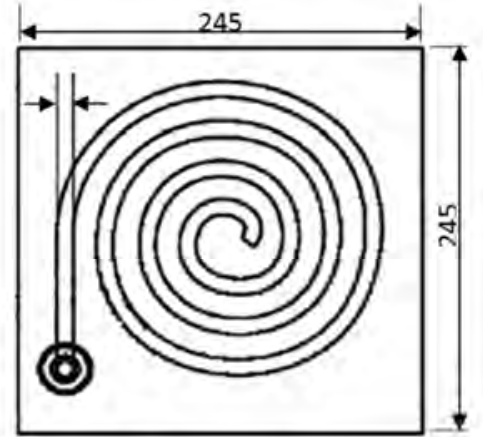

a)

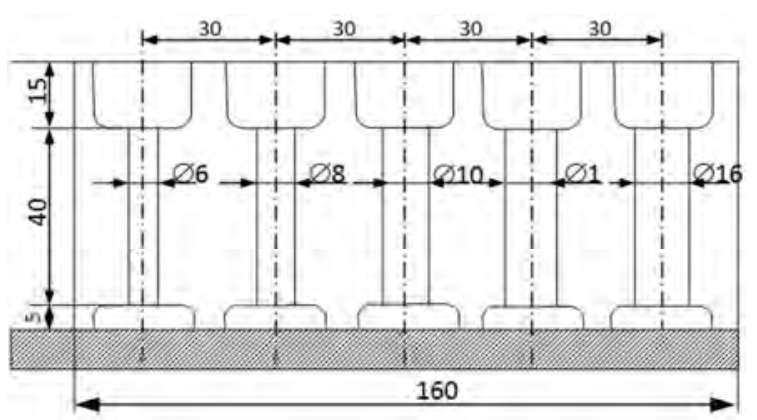

b)

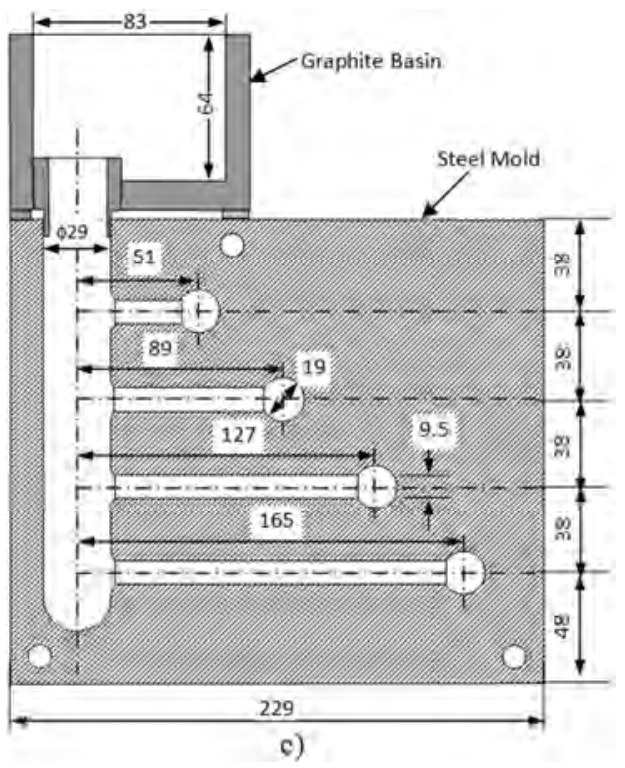

Figure 1. Molds used in experiments a) Fluidity Spiral b) Different diameters same lengths hot tear mold c) Same diameters, different lengths hot tear mold.

\section{Results and Discussion}

\subsection{Microstructure}

Figures 2 (a-d) show microstructure images of AZ91 alloy and additional $\mathrm{Pb}$ content. When AZ91 microstructure (Figure 2a) is examined, it is seen that the structure is formed mainly by eutectic and intermetallic phases extending along the grain boundaries in the main matrix of $\alpha-\mathrm{Mg}$. These phases are the $\mathrm{Mg}_{17} \mathrm{Al}_{12}(\beta)$ intermetallics with $\mathrm{Mg}-\mathrm{Al}(\alpha+\beta)$ 
eutectic. The morphological structure of the $\mathrm{Mg}_{17} \mathrm{Al}_{12}$ phase is similar to the literature $[17,18]$ and is generally seen as a similar structure to the Chinese script. The addition of $\mathrm{Pb}$ to the alloys caused a decrease in the amount of $\alpha+\beta$ eutectic. $\mathrm{Pb}$ in the AZ91 alloy has a high solubility of $\sim 45 \%$ [19], possibly resulting in a solid solution in the structure rather than $\mathrm{Al}$ displacement. It is expected that $\mathrm{Mg}_{2} \mathrm{~Pb}$ phase

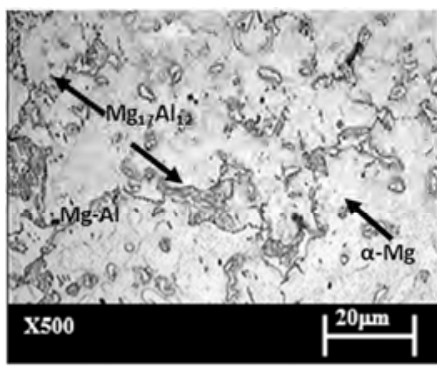

a)

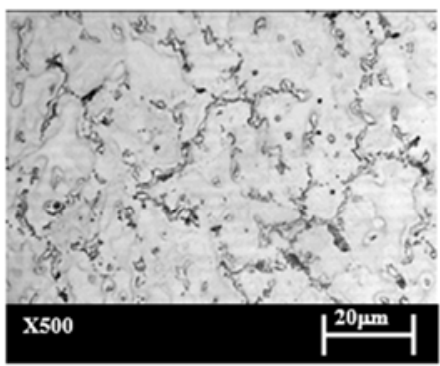

c) appears in small quantities addition of $\mathrm{Pb}$, as well as intermetallic phase $\mathrm{Mg}_{17} \mathrm{Al}_{12}$ in $\mathrm{Pb}$ additives. However, there is no information on the formation of $\mathrm{Mg}_{2} \mathrm{~Pb}$ phase with $\mathrm{Pb}$ addition in AZ91 alloy in literature. Srinivasan et al. [20] investigated the effect of $2 \% \mathrm{~Pb}$ addition on AZ91 on aging and did not mention $\mathrm{Mg}_{2} \mathrm{~Pb}$ here.

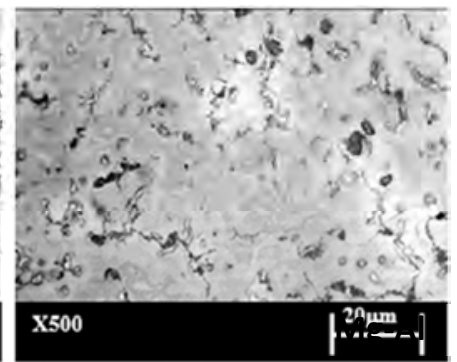

b)

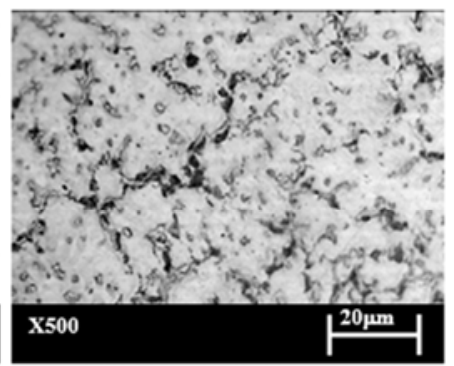

d)

Figure 2. Optical microstructures of the alloys: a) $A Z 91, b) A Z 91+0.2 P b, c) A Z 91+0.3 P b$, d) $A Z 91+0.4 P b$.

\subsection{Casting Properties}

\subsubsection{Fluidity}

Figure 3 shows the fluidity values of the alloys as a function of $\mathrm{Pb}$ contents. Fluidity increased as increasing $\mathrm{Pb}$ contents. The fluidity length of the AZ91 alloy was $17.5 \mathrm{~cm}$ while it increased by $20 \mathrm{~cm}$ with the addition of $0.4 \mathrm{wt} . \% \mathrm{~Pb}$. It is known that enthalpy, oxide formation, surface tension, and solidification time are the parameters affecting fluidity. For this reason, it is expected that $\mathrm{Pb}$ decreases the surface tension of $\mathrm{Mg}$ as a surface active element and accordingly increases the fluidity [21]. The $\mathrm{Pb}$ evaporation grade is a low element and may cause the $\mathrm{MgO}$ oxide formation on the surface to weaken or break during casting due to evaporation $[22,23]$. Therefore, weak or broken $\mathrm{MgO}$ can lead to increased flow.

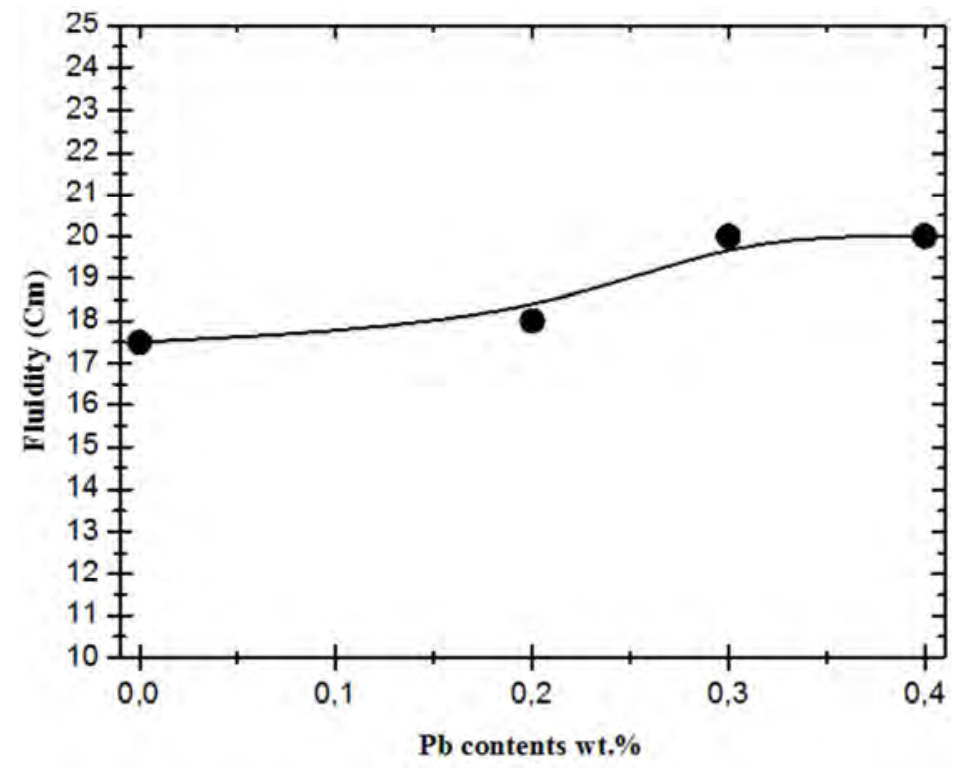

Figure 3. Fluiditiy values of the alloys as a function of $\mathrm{Pb}$ contents. 


\subsubsection{Hot Tearing Tests}

The hot tear test results were given as two different methods with the same lengths, different diameters and different lengths, same diameters. In the literature, which method is more effective has not been reported, so two different methods will be given comparatively to try to understand which is more effective.

\section{(i) The Mold with Different Diameter, Same Lengths}

Figure 4 shows the results of the hot tear test of the AZ91 alloy and additions of $\mathrm{Pb}$ element, after casting in the molds of different diameters, same lengths. Hot tears disappeared in all of the samples of $0.4 \mathrm{~mm} \mathrm{~Pb}$ and $16 \mathrm{~mm}$ diameter with a diameter of $12 \mathrm{~mm}$ while all the samples with a diameter of $10 \mathrm{~mm}$ had a hot tear with $\mathrm{Pb}$ additions.

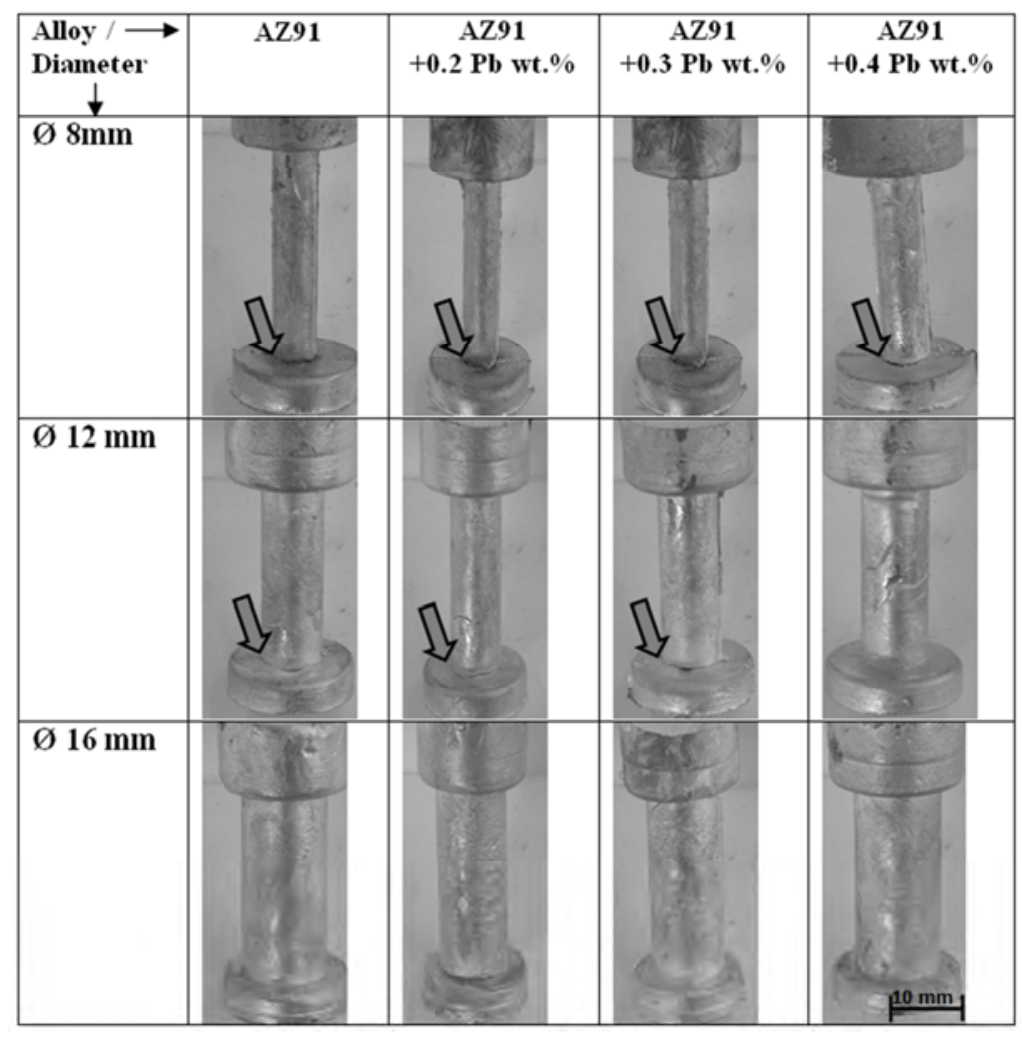

Figure 4. Hot tear images of the alloys using the mold with different diameter, same lengths.

\section{(ii) The Mold with Same Diameters Different Lengths}

Figure 5 shows the results of the hot tear test after casting in the molds of different lengths same diameters with the additions of the Pb element to the AZ91 alloy. As can be seen in Figure 5, the longest arm in the mold is located at the bottom and hot tears for each alloy are visible on this arm adjacent to the runner. Hot tearing is not visible in other shorter arms. This indicates that the sensitivity of the long arm to hot tear is more effective than that of the other arms, which is explained by the fact that the shortening is longer in the long arm.
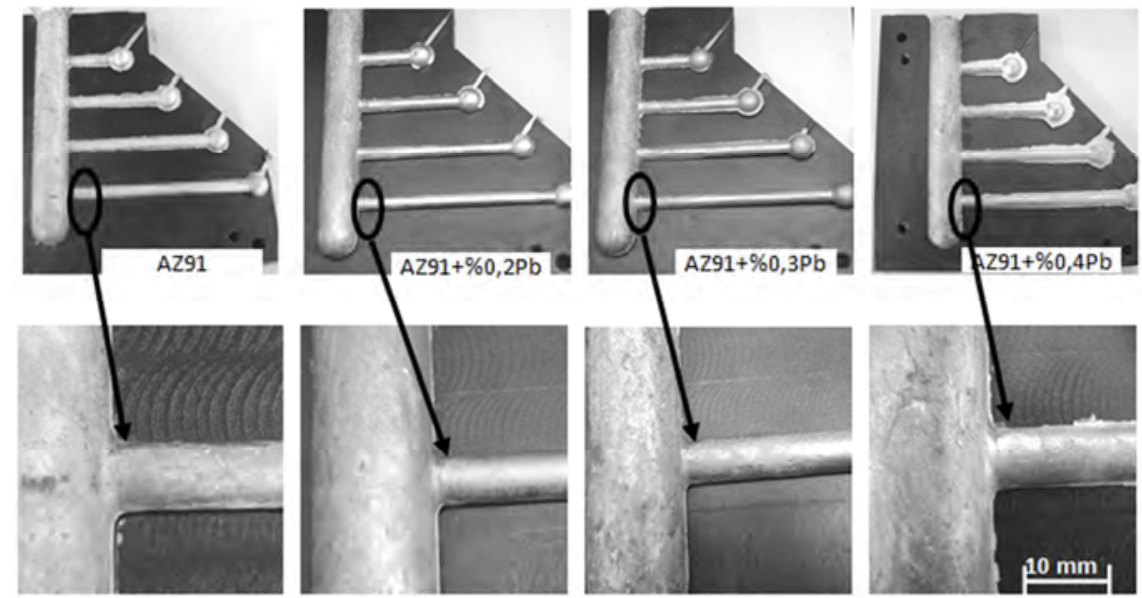

Figure 5. Hot tear images, the mold with same diameters, different lengths. 
As the sample diameter increases, hot tearing did not occur. This may be due to the mold design. Casting in the same diameter, different length method is done with large diameter vertical runner and arms are in horizontal position. It may be less common for hot tearing as the upper arms may be subject to preheating and unit shortening may be less during runner filling. On the other hand, casting is done vertically in different diameters and the effect of preheating can be negligible compared to other method.

\section{Conclusion}

1. Microstructure studies showed that the addition of $\mathrm{Pb}$ to the alloys caused a decrease in the amount of $\alpha+\beta$ eutectic.

2. Fluidity increased as increasing $\mathrm{Pb}$ contents. The fluidity length of the AZ91 alloy was $17.5 \mathrm{~cm}$ while it increased by $20 \mathrm{~cm}$ with the addition of $0.4 \mathrm{wt} . \% \mathrm{~Pb}$.

3. Hot tearings were observed in "the mold with different diameter, same lengths" in 0.2 wt.\% and 0.3 wt. $\% \mathrm{~Pb}$ additions, while hot tearing was not observed when this ratio increased to $0.4 \%$ for the $12 \mathrm{~mm}$ diameter test specimens. There was also not hot tearing were observed in any sample when the sample diameter was $16 \mathrm{~mm}$.

4. Hot tearings did not occur in "the molds with different lengths same diameters" as the sample diameter increases. This may be due to the mold design.

\section{Acknowledgements}

This work was financially supported by the Scientific Research Projects Coordination Unit (BAP) with Project number KBU-BAP-17-YD-315, Karabuk University, Karabuk, Turkey.

\section{References}

[1] G. S. Cole, Summary of Magnesium Vision 2020: A North American Automotive Strategic Vision for Magnesium, Magnesium Technology, ed. R. S. Beals et al., 35-40, (2007).

[2] C. Blawert N. Hort, K. U. Kainer, Automotive Applications of Magnesium and Its Alloys, Trans. Indian Inst. Met. Vol. 57, 397-408, (2004).

[3] G. S. Cole and A. M. Sherman, Light weight materials for automotive applications. Materials Characterization, 35, (1) 39, (1995).

[4] D. Eliezer, E. Aghion, F. H. Froes, Magnesium Science, Technology and Applications, Advanced Performance Materials, 201-212, (1998).

[5] L. P. Barber, Characterization of the Solidification Behavior and Resultant Microstructures of Magnesium-Aluminum Alloys, A Thesis of Master, Worcester Polytechnic Institute, Worcester, 10-46 (2004).

[6] Z. Zhang, Development of Magnesium-Based Alloys for Elevated Temperature Applications, Doctor of These, Faculte
Des Sciences Et De Genie Universite, Quebec-Canada, 2-75, (2000).

[7] S. Johansson, Magnesium Alloys, Summary of chapter 1-7 in Light alloys by I. J. Polmear, Engineering Materials, 5, 17-20, (2002).

[8] H. K. Kazdal, Magnezyum Alaşımları: Otomotiv Endüstrisinde Uygulaması ve Geleceği, Tubitak, Marmara Araştırma Merkezi, Kocaeli, 3-39, (1999).

[9] T. Aizawa, R. Song, Mechanically induced reaction for solidstate synthesis of $\mathrm{Mg}_{2} \mathrm{Si}$ and $\mathrm{Mg}_{2} \mathrm{Sn}$, Intermetallics, 14, 382391, (2006).

[10] M. O., Pekgüleryüz, A. A., Kaya Creep resistant magnesium alloys for power train aplications, Advanced Engineering Materials, DGM, 5, 197-221, (2004).

[11] N. Balasubramani, A. Srinivasan, U. T. S., Pillai, B. C., Pai, Effect of $\mathrm{Pb}$ and $\mathrm{Sb}$ additions on the precipitation kinetics of AZ91 magnesium alloy Mater. Sci. Eng. A 457, 275-281, (2007).

[12] Y. Guangyin, S. Yangshan, D. Wenjiang, Effects of bismuth and antimony additions on the microstructure and mechanical properties of AZ91 magnesium alloy Mater. Sci. Eng. A 308, 38-44, (2001).

[13] OECD Nuclear Energy Agency, Science Reports, Chapter 13, (2007).

[14] M.Ünal, An investigation of casting properties of magnesium alloys, Ph.D Thesis, Gazi University, Ankara, Turkey, (2008).

[15] M. D., Sabatino, F. Syvertsen, L. Arnberg, A. Nordmark, An improved method for fluidity measurement by gravity casting of spirals in sand moulds, International Journal of Cast Metals Research, 18, 59-62, (2005).

[16] G. Cao, S. Kou, Hot cracking of binary Mg-Al alloy castings, Mater. Sci. Eng. 417, 230-238, (2006).

[17] Q. Wang, Y. Lu, X. Zeng, W. Ding, Y. Zhu, Q. Li, L. Jie, Study on the fluidity of AZ91+xRE magnesium alloy, Mater. Sci. Eng. 271: 109-115, (1999).

[18] C. D. Lee, K. S. Shin, Effect of microporosity on the tensile properties of AZ91 magnesium alloy, Acta Materialia, 55, 4293-4303, (2007).

[19] K. T. Kashyap, C. Ramachandra, M. Sujatha, B. Chatteri, Role of diffusional coherency strain theory in the discontinuous precipitation in Mg-Al alloy, Mater. Sci. 23, 39-45, (2000).

[20] A. Srinivasan, U. T. S. Pillai, B. C. Pai, Effect of Pb addition on ageing behavior of AZ91 magnesium alloys, Mater. Sci. Eng. 452, 87-92, (2006).

[21] B. Gravert, Y. Yu, K. Nisancioglu, Passivity Breakdown of Aluminum Alloys by Surface Enrichment of Group IIIA-VA Trace Elements, 9th International Symp. Paris, 627-632, (2006).

[22] H. Westengen, T. K. Aune, Magnesium Casting Alloys, Magnesium Technology, Springer, 145-204, (2006).

[23] S. Candan, M. Unal, M, Turkmen, E. Koc, Y. Turen, E. Candan, Improvement of mechanical and corrosion properties of magnesium alloy by lead addition, Mater. Sci. Eng. A, 501, 115-118, (2009). 